\title{
S0038-1098(96)00064-6 \\ VISIBLE PHOTOLUMINESCENCE FROM LOW TEMPERATURE DEPOSITED HYDROGENATED AMORPHOUS SILICON NITRIDE
}

\author{
Atilla Aydınl, Ali Serpengüzel and Didem Vardar \\ Department of Physics, Bilkent University, Bilkent, Ankara, 06533,Turkey
}

(Received 25 September 1995; accepted 23 January 1996 by R. Fieschi)

\begin{abstract}
Hydrogenated amorphous silicon nitride $\left(\mathrm{a}-\mathrm{SiN}_{\mathrm{x}}: \mathrm{H}\right)$ samples have been prepared by plasma enhanced chemical vapor deposition (PECVD) using a mixture of silane $\left(\mathrm{SiH}_{4}\right)$, nitrogen and ammonia $\left(\mathrm{NH}_{3}\right)$. Most films exhibit visible photoluminescence (PL) and some emit strong $\mathrm{PL}$ after annealing. While films grown without $\mathrm{NH}_{3}$ exhibit PL in the deep red, those grown with $\mathrm{NH}_{3}$ show PL in the green. The PL properties of these films with no oxygen $(\mathrm{O})$ content are similar to those of silicon oxide $\left(\mathrm{SiO}_{\mathrm{x}}\right)$ films and porous $\mathrm{Si}$. Using infrared and $\mathrm{X}$-ray Photoelectron Spectroscopy, we suggest that $\mathrm{PL}$ from a-SiN $\mathrm{N}_{\mathrm{x}} \mathrm{H}$ films originate from Si clusters which form during PECVD and crystallize upon annealing. We propose that the presence of $O$ is not necessary for efficient PL.
\end{abstract}

Keywords: A. thin films, D. optical properties, E. luminescence.

Recently, strong room temperature luminescence of porous silicon ( $\mathrm{Si}$ ) obtained by both stain and anodically etched crystalline $\mathrm{Si}$ has been investigated. The process is promising for light emitting devices, since it can be tuned to different wavelengths ${ }^{1}$, and can be integrated into the existing Si microelectronics technology. The original proposal by Canham ${ }^{2}$, that light emission occurs due to carrier confinement in narrow columns of crystalline $\mathrm{Si}$, has been challenged with the proposals of surface effects ${ }^{3}$ and siloxene 4 as the source of light emission. In addition to the $\mathrm{Si}$ columus that form during the anodization process, both microcrystalline $\mathrm{Si}$ with average size of a few nanometers, and amorphous material have been observed 5 . The photoluminescence (PL) properties of porous $\mathrm{Si}$ have been attributed to Si columns, microcrystallites, and $\mathrm{H}$ and/or $\mathrm{O}$ containing amorphous material ${ }^{3}$. Amorphous hydrogenated $\mathrm{Si}$ (a-Si:H) also shows visible PL at roon temperature, when prepared by chenical vapor deposition 6 . Furthermore, a-SiO $: \mathrm{H}$ samples incorporating various concentrations of $O$ have showed visible $P L$ at room temperature 7 . Carrier recombination has been invoked to explain PL in such cluster structures embedded in amorphous material ${ }^{8}$. Since porous Si may contain all of these materials (i.e., Si columns, microcrystallites, and $\mathrm{H}$ and/or $\mathrm{O}$ containing amorphous material), it is to be suspected that the origin of PL in porous Si may be the same or similar to those observed in a-Si:H or $\mathrm{a}-\mathrm{SiO}_{\mathbf{X}}: \mathrm{H}$. Initial experiments of low temperature oxidation of porous $\mathrm{Si}$, showing poor $\mathrm{PL}$ intensities have been superseded by high temperature oxidation experiments, which gave strong visible luminescence at room temperature 9 . Furthernore, oxidation via boiling in water has resulted in blue $\mathrm{PL}$ from porous $\mathrm{Si}^{10}$. Therefore, it is of interest to study, whether a non-oxygen containing material like a-SiN ${ }_{X}: H$ has the same $P L$ properties as porous Si and $\mathrm{Si}$ rich a-SiO${ }_{X}: \mathrm{H}$.

In this Communication, we present the results of PL and Fourier Transform Infrared (FTIR) characterization of both as-grown and rapid thermal processor (RTP) annealed a-SiN $\mathrm{S}_{\mathrm{X}}: \mathrm{H}$ deposited by plasma enhanced chemical vapor deposition (PECVD). X-ray Photelectron Spectroscopy was also employed to determine the valency of $\mathrm{Si}$ and $\mathrm{N}$.

a-SiN $\mathrm{X}_{\mathrm{X}}: \mathrm{H}$ samples have been prepared on (001) $\mathrm{Si}$ substrates by PECVD at $100^{\circ} \mathrm{C}$ with nitrogen $\left(\mathrm{N}_{2}\right)$ balanced $2 \%$ silane $\left(\mathrm{SiH}_{4}\right)$, and pure ammonia $\left(\mathrm{NH}_{3}\right)$ as the source. Other substrates such as quartz were not used to avoid the possibility of $O$ uptake from the substrate during high temperature annealing. No intentional $O$ was introduced into the chamber. The flow ratio of $\mathrm{NH}_{3} /\left[\left(2 \% \mathrm{SiH}_{4}+98 \% \mathrm{~N}_{2}\right)+\mathrm{NH}_{3}\right]$ defined as $\mathbf{R}$, was varied from 0 to 0.2 . The $\mathrm{rf}$ power and chamber pressure were $10 \mathrm{~W}$ and 1 Torr, respectively. The thicknesses of the samples were 
kept at approximately $500 \mathrm{~nm}$. Annealing was done immediately in forming gas environment using a RTP for 10 minutes up to $800{ }^{\circ} \mathrm{C}$ with $100{ }^{\circ} \mathrm{C}$ intervals . PL was measured at room temperature using a 1-m double monochromator, equipped with a cooled GaAs PMT and standard photon counting electronics. For PL excitation the $457.9 \mathrm{~nm}$ and $514.5 \mathrm{~nm}$ lines of an $\mathrm{Ar}^{+}$laser were used.

Figure 1 shows the IR spectra of samples deposited with differing values of $R$ ranging from $\mathbf{R}=0$ to $\mathbf{R}=0.2$. Several peaks are readily identified as $\mathrm{SiN}-\mathrm{H}_{2}$ stretching $\left(-3450 \mathrm{~cm}^{-1}\right), \quad \mathrm{Si}_{2} \mathrm{~N}-\mathrm{H}$ stretching $\left(\sim 3350 \mathrm{~cm}^{-1}\right), \mathrm{N}_{2} \mathrm{Si}-\mathrm{H}$ stretching ( 2150 $\left.\mathrm{cm}^{-1}\right)$, SiN- $\mathrm{H}_{2}$ bending $\left(\sim 1550 \mathrm{~cm}^{-1}\right)$, and $\mathrm{Si}_{2} \mathrm{~N}-\mathrm{H}$ rocking $\left(\sim 1170 \mathrm{~cm}^{-1}\right)$ modes. The reactive nature of $\mathrm{NH}_{3}$ becomes obvious, when IR spectra of samples grown with and without $\mathrm{NH}_{3}$ are compared. For the samples grown with $\mathrm{R}=0$, we observe very weak $\mathrm{Si}_{2} \mathrm{~N}-\mathrm{H}$ stretching and rocking modes. As $\mathbf{R}$ increases, the $\mathrm{Si}_{2} \mathrm{~N}-\mathrm{H}$ modes become stronger. In fact, careful inspection of the spectra shows that increasing $R$ results in an increase of ( $\mathrm{Si}$ bonded) $\mathrm{N}$ $\mathrm{H}$ bonds, and a decrease of $\mathrm{Si}-\mathrm{H}$ bonds. It is possible to estimate $\mathrm{Si}-\mathrm{H}$ and ( $\mathrm{Si}$ bonded) $\mathrm{N}-\mathrm{H}$ bond concentrations using the absorbances at $\sim 2150 \mathrm{~cm}^{-1}$ and $-3350 \mathrm{~cm}^{-1}$, respectively ${ }^{11}$. We find that for asgrown samples with $\mathbf{R}=0, \mathrm{Si}-\mathrm{H}$ concentration is $3.3 \times 10^{22} \mathrm{~cm}^{-3}$, while $\mathrm{N}-\mathrm{H}$ concentration is $2.3 \times 10^{21} \mathrm{~cm}^{-3}$. Addition of $\mathrm{NH}_{3}$ changes this drastically, reducing the $\mathrm{Si}-\mathrm{H}$ concentration by a factor of 3 , while increasing the $\mathrm{N}-\mathrm{H}$ concentration by more than an order of magnitude to $3.5 \times 10^{22} \mathrm{~cm}^{-}$ 3 , for samples grown with $\mathbf{R}=0.05$.

In Fig.1, the region of $800-900 \mathrm{~cm}^{-1}$ may have contributions from several sources. Since the

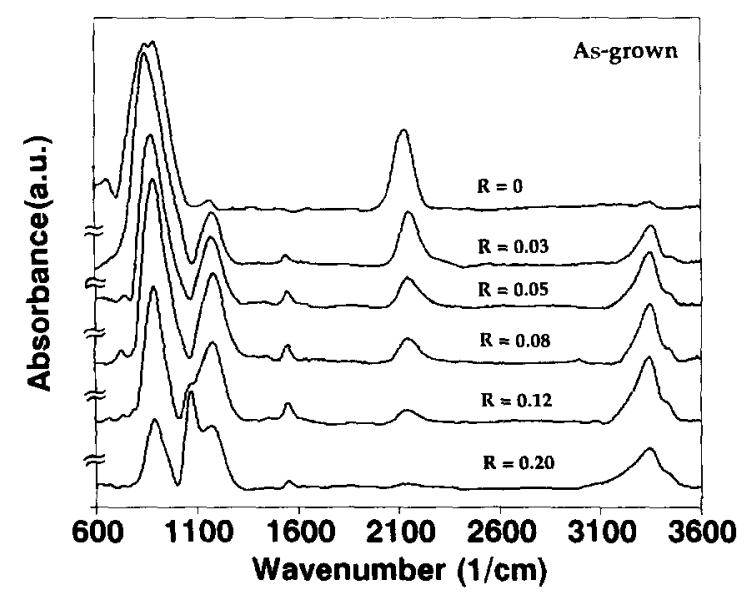

Fig. 1. IR absorption spectra of as grown a$\mathrm{SiN}_{\mathbf{X}}: \mathrm{H}$ films as a function of $\mathbf{R}$. The spectra were taken within 24 hours of growth. deposition temperature was $100{ }^{\circ} \mathrm{C}$, as-grown samples may contain polysilanes ${ }^{12}$. A detailed analysis to differentiate among various bonding configurations of Si-H shows that, peaks at $2000 \mathrm{~cm}^{-}$ 1 and $630 \mathrm{~cm}^{-1}$ are due to monohydrides (SiH), 2090 $\mathrm{cm}^{-1}, 875 \mathrm{~cm}^{-1}, 630 \mathrm{~cm}^{-1}$ to disilanes $\left(\mathrm{SiH}_{2}\right), 2100 \mathrm{~cm}^{-}$ $1,890 \mathrm{~cm}^{-1}, 845 \mathrm{~cm}^{-1}, 630 \mathrm{~cm}^{-1}$ to $\left(\mathrm{SiH}_{2}\right)_{\mathrm{n}}$, and 2140 $\mathrm{cm}^{-1}, 907 \mathrm{~cm}^{-1}, 862 \mathrm{~cm}^{-1}, 630 \mathrm{~cm}^{-1}$ to $\mathrm{SiH}_{3}, 13$. This analysis suggests the presence $\left(\mathrm{SiH}_{2}\right)_{n}$ in our samples. However, contributions of the $\mathrm{Si}-\mathrm{N}$ in plane stretching vibration starting at $840 \mathrm{~cm}^{-1}$ and shifting up to $890 \mathrm{~cm}^{-1}$ is also in the same range. In the case of the $R=0$ sample, we observe that, the contribution of the polysilanes around the $\mathrm{Si}-\mathrm{N}$ in plane stretching vibration decreases as we anneal the samples up to $800{ }^{\circ} \mathrm{C}$ (not shown). In fact, as soon as $\mathbf{R}$ becomes $\geq 0.02$, the contribution of the polysilanes to the peak at $855 \mathrm{~cm}^{-1}$ is no longer distinguishable. This peak shifts to higher frequencies, as $\mathrm{NH}_{3}$ concentration is increased. At higher concentrations of $\mathrm{NH}_{3}$, we also witness the appearance of a peak at $1074 \mathrm{~cm}^{-1}(R=0.12$ and 0.2$)$, which we do not observe at lower concentrations of $\mathrm{NH}_{3} \quad(\mathbf{R}<0.12)$. This peak is identified as the antisymmetric stretching mode of $\mathrm{Si}-\mathrm{O}-\mathrm{Si}$. This is not unusual, since these FTIR measurements were done within 24 hours of growing the samples, and it is known that at high concentrations of $\mathrm{NH}_{3}$ rapid oxidation of low temperature deposited a-SiN $: H$ takes place. ${ }^{13}$ However, we note that, a-SiN $\mathrm{X}_{\mathrm{X}}: \mathrm{H}$ films become resistant to oxidation (for at least up to four months) after annealing at temperatures above $600^{\circ}$ C.

Figure 2 shows the IR spectra of samples with $\mathbf{R}=0.05$ annealed from $400{ }^{\circ} \mathrm{C}$ to $800{ }^{\circ} \mathrm{C}$. Each annealing was done on a separate sample. In these

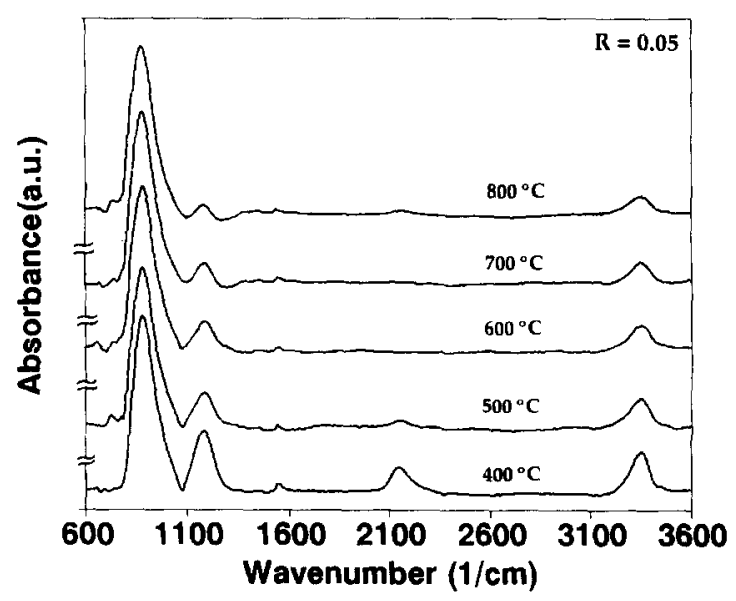

Fig. 2. IR absorption spectra of samples grown with $\mathbf{R}=0.05$ and annealed at various temperatures. 
samples in addition to the dominant $\mathrm{Si}-\mathrm{N}$ in plane stretching mode $\left(\sim 880 \mathrm{~cm}^{-1}\right)$, we also observe the $\mathrm{Si}_{2} \mathrm{~N}-\mathrm{H}$ rocking $\left(\sim 1170 \mathrm{~cm}^{-1}\right)$, the $\mathrm{SiN}-\mathrm{H}_{2}$ bending $\left(\sim 1550 \mathrm{~cm}^{-1}\right)$, the $\mathrm{N}_{2} \mathrm{Si}-\mathrm{H}$ stretching $\left(\sim 2150 \mathrm{~cm}^{-1}\right)$, and the $\mathrm{Si}_{2} \mathrm{~N}-\mathrm{H}$ stretching mode $\left(\sim 3350 \mathrm{~cm}^{-1}\right)$. As the annealing temperature is increased, we observe the effusion of $\mathrm{H}$ through the decrease of $\mathrm{N}-\mathrm{H}$ and $\mathrm{Si}-\mathrm{H}$ related peaks $\left(\sim 3350 \mathrm{~cm}^{-1}, \sim 2150 \mathrm{~cm}^{-1}, \sim 1550 \mathrm{~cm}^{-1}\right.$, and $\left.\sim 1170 \mathrm{~cm}^{-1}\right)$. However, while most of the $\mathrm{Si}$ bonded $\mathrm{H}$ is driven out during annealing (as evidenced by a very weak peak at $\sim 2150 \mathrm{~cm}^{-1)}$, a lot of $\mathrm{N}-\mathrm{H}$ bonds are still intact 14,15 even after $800^{\circ} \mathrm{C}$ annealing (note the remaining $\mathrm{Si}_{2} \mathrm{~N}-\mathrm{H}$ peaks at $\sim 3350 \mathrm{~cm}^{-1}$ and $\sim 1170 \mathrm{~cm}^{-1}$ ). We have also estimated $\mathrm{Si}-\mathrm{H}$ and $\mathrm{N}-\mathrm{H}$ bond concentrations as a function of annealing temperature. We find that annealing the samples grown with $\mathrm{R}=0.05$ at $800^{\circ} \mathrm{C}$ reduces $\mathrm{Si}-\mathrm{H}$ concentration by a factor of 10 , and the $\mathrm{N}-\mathrm{H}$ concentration by only a factor of 3 . This is to be expected, since the $\mathrm{N}-\mathrm{H}$ bond energy is $4.05 \mathrm{eV}$, while the $\mathrm{Si}-\mathrm{H}$ bond energy is $3.1 \mathrm{eV} .16$

Figure 3 shows the room temperature PL spectra of the samples of Fig. 2 (with $R=0.05$ annealed from $400^{\circ} \mathrm{C}$ to $800^{\circ} \mathrm{C}$ ). PL peak position from as-grown samples with $R>0$ is in the vicinity of $500 \mathrm{~nm}$. The FWHM of these spectra are typically about $0.5 \mathrm{eV}$. In the inset of Fig. 3, we show the observed red shift of the PL peak position upon annealing for samples with $R=0.05$. The data for the PL peak position is compiled from four sets of samples grown and annealed under the same conditions. Even though there is some scatter in the data( as shown with a bar

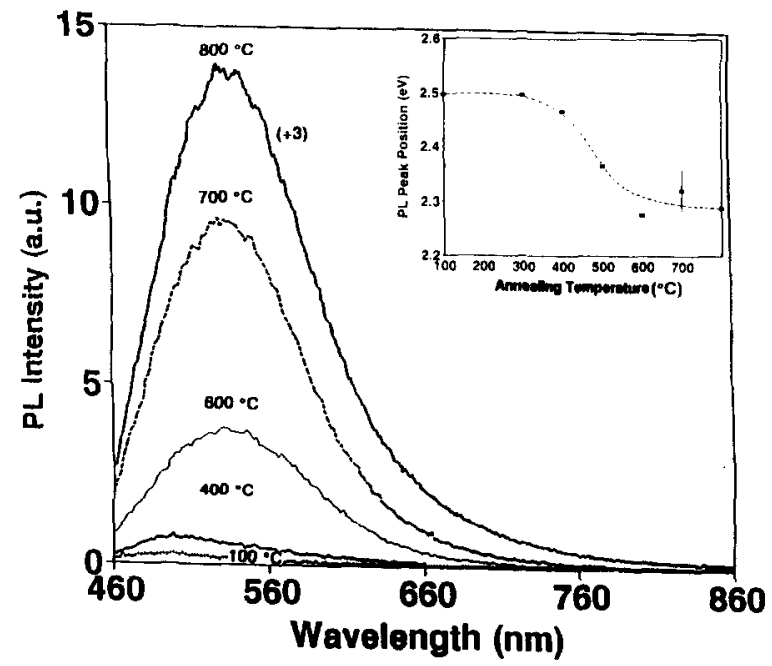

Fig.3. PL spectra of samples grown with $\mathbf{R}=0.05$ annealed at various temperatures. ThePL peak position as a function of annealing temperature is given in the inset. The typical standard deviation of the data is shown for the data point at $700^{\circ} \mathrm{C}$. for the data point at $700{ }^{\circ} \mathrm{C}$ ), the red shift upon annealing is evident. After annealing at and above $600^{\circ} \mathrm{C}$, the saniples with $\mathrm{R}=0.05$ exhibit PL strong enough to be observed by the naked eye. For one set of samples, special attention was paid to perform both the FTIR and the PL spectroscopy immediately after the growth and annealing to clearly establish the presence of the PL before any oxygen contamination could take place. While we can not entirely rule out the presence of $O$ on the microscopic level, the fact that, high temperature annealed samples do not show signs of $O$ contamination as detected by FTIR, lead us to conclude that $O$ does not play a significant role in the mechanism resulting in visible PL. However, we note that partially oxidized samples at lower temperatures also exhibit visible PL.

We have also recorded the PL spectra of samples with $\mathbf{R}=0$ (Fig:4). The spectra have been normalized to emphasize the shifts in the PL peak position. These samples, have broader PL spectra extending from the blue to near-IR, which are sinilar to porous $\mathrm{Si}^{3}$. The PL spectrum for the as grown sample peaks around $695 \mathrm{n}$. The peak red shifts up to $750 \mathrm{~nm}$ upon annealing up to $400^{\circ} \mathrm{C}$, while preserving the general shape of the PL spectra. The PL spectrum of the sample amnealed at $400{ }^{\circ} \mathrm{C}$ has a tail extending to $900 \mathrm{~nm}$ (the linit of our detection system). These samples do not exhibit any PL signal, within our spectral detection range, when annealed at $500^{\circ} \mathrm{C}$ or higher temperatures. The loss of PL signal upon annealing at $500{ }^{\circ} \mathrm{C}$ and higher temperatures correlates well with the effusion of $\mathrm{H}$ from these samples as deduced from FTIR measurements (not shown). In the FTIR measurements of the samples annealed at $500^{\circ} \mathrm{C}$, we find that, $\mathrm{Si}-\mathrm{H}$ concentration

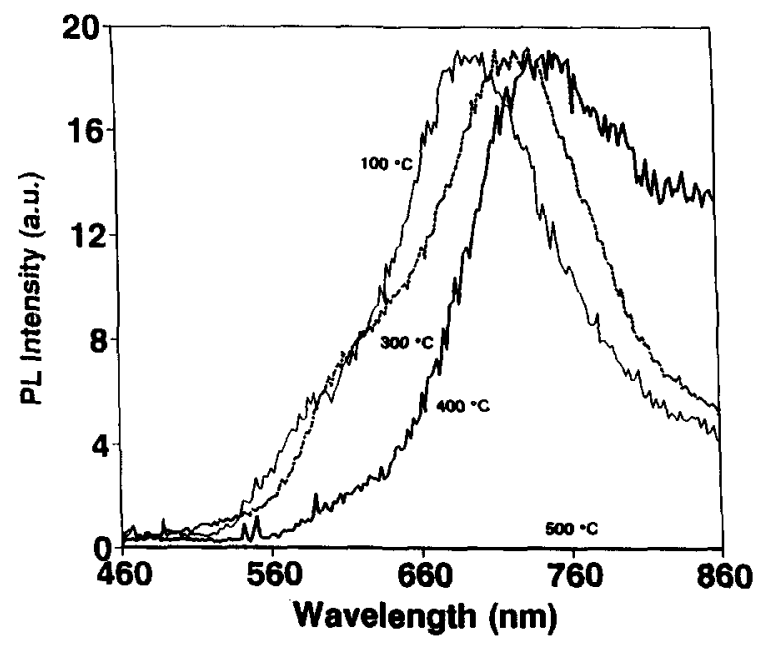

Fig.4. PL spectra of samples grown with $R=0$ and annealed up to $500^{\circ} \mathrm{C}$. 
decreases by a factor of 5.8 while the already weak $\mathrm{N}-\mathrm{H}$ concentration falls below our detection limit.

In order to understand the valency of the Si and $N$ making up the samples, XPS analysis (not shown) of samples grown with $R=0$ and 0.05 was also performed. The Si $2 p$ spectra of both as-grown and $800^{\circ} \mathrm{C}$ annealed samples were compared. In the case of the as-grown sample with $R=0.05$, we observe a well resolved single symmetric peak centered at 104 $\mathrm{eV}$; for the same sample annealed at $800^{\circ} \mathrm{C}$, we observe two peaks: one centered at $104 \mathrm{eV}$, and another small one at $100 \mathrm{eV}$. The large peak at 104 $\mathrm{eV}$ represents the bonded $\mathrm{Si}$. The small peak at 100 $\mathrm{eV}$, whose binding energy compares well with the corresponding Si $2 \mathrm{p}$ peak for bulk Si $(99.12 \mathrm{eV})$, establishes the presence of zero valent $\mathrm{Si}$. Note that binding energy of zero valent $\mathrm{Si}$ in $\mathrm{SiN}_{\mathrm{X}}$ is upshifted from that of $\mathrm{Si} 2 \mathrm{p}$ in bulk $\mathrm{Si}^{19}$. The low energy Si $2 \mathrm{p}$ peak is also present much more strongly in both the as-grown and the annealed samples grown with $\mathbf{R}=0$, again pointing to the presence of zero valent $S i$.

In Fig. 5, we display the PL peak intensity as a function of $\mathbf{R}$. In general, we observe that for all compositions with $\mathbf{R} \neq 0$, increasing annealing temperatures lead to increasing $\mathrm{PL}$ intensities. We also observe that, in the vicinity of $R=0.05$, there is a sharp increase of the PL peak intensity for all annealing temperatures. The only exception to this are the samples grown with $\mathbf{R}=0$. For as-grown samples we observe PL in the deep red which shows a five fold increase upon annealing at $300{ }^{\circ} \mathrm{C}$, falling sharply when annealed at $400^{\circ} \mathrm{C}$. At $500^{\circ} \mathrm{C}$ and higher temperatures, $\mathrm{PL}$ intensity is either totally quenched or shifts beyond $900 \mathrm{~nm}$ ( spectral limit of our monochromator) with much reduced

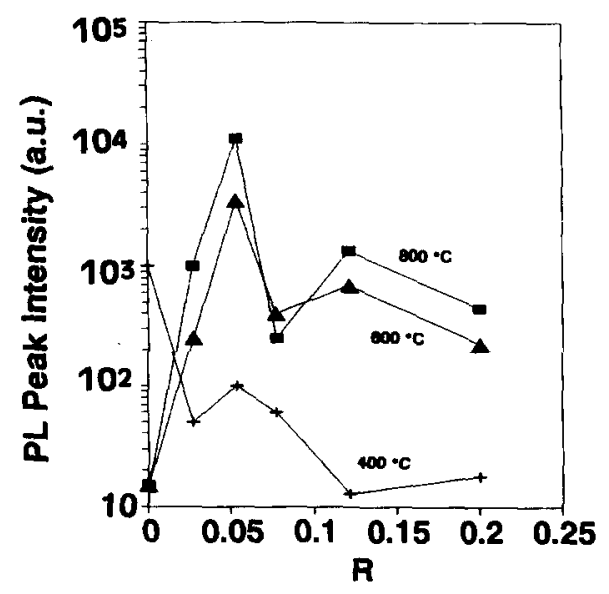

Fig.5. PL peak intensity as a function of the flow ratio $\mathbf{R}$ for various annealing temperatures. intensity. We also note that increasing $\mathbf{R}$ values beyond $R=0.05$ decreases $P L$ intensity, which correlates well with decreasing $\mathrm{Si}-\mathrm{H}$ bond concentration.

We begin interpreting our data for samples grown with $\mathrm{R}=0$. It is known that, $a-\mathrm{SiN}_{\mathrm{x}}: \mathrm{H}$ films deposited on low temperature substrates show columnar growth morphology with material in the columns assumed to be a-Si with isolated $\mathrm{N}$ atom bonding sites ${ }^{17}$. The connecting material between the columns is $\left(\mathrm{SiH}_{2}\right)_{n}$. Such a picture, is not inconsistent with the model proposed by Brodsky 8 as well as the observation of Bruesch et.al. ${ }^{18}$ in the case of $\mathrm{a}-\mathrm{SiO}_{\mathbf{x}}: \mathrm{H}$. We propose that, our samples consist of small a-Si clusters in a matrix of a-Si:H and $a-S_{i N}: H$. The regions with $\mathrm{Si}-\mathrm{N}$ and $\mathrm{Si}-\mathrm{H}$, having larger energy gaps due to strong $\mathrm{Si}-\mathrm{H}$ and $\mathrm{Si}-\mathrm{N}$ bonds, isolate these a-Si clusters, and form barrier regions around them. The weak $\mathrm{PL}$, which is observed in the deep red originates from these a-Si clusters. With increasing annealing temperatures, PL becomes stronger due to crystallization of the clusters and shifts into the IR due to $\mathrm{H}$ effusion and increasing crystallite size. Further increase of the annealing temperature results in the increase of the crystallite size, causing the quenching of the visible and near-IR PL. At this point, we believe that, most of the Si crystallites are large enough to show bulklike behavior and no longer luminesce in the visible. This picture is further supported by the presence of zero valent $S_{i}$ in the XPS data of the samples with $\mathbf{R}=0$ both before and after annealing. In fact the very broad XPS peak, which is observed from the asgrown samples, is actually composed of multiple peaks corresponding to bonded and zero valent $S i$.

Addition of $\mathrm{NH}_{3}$ into the chamber changes the situation dramatically. First, we observe from the FTIR data that, both $\mathrm{H}$ and $\mathrm{N}$ uptake of the samples during the growth increases. Second, the PL peak position shifts to shorter wavelengths $(\sim 500 \mathrm{~nm})$ by more than $150 \mathrm{~nm}$. We find that, annealing the samples increases PL efficiency, which again correlates well with $\mathrm{H}$ effusion. However, we find that, there still remains much $\mathrm{H}$ in the samples, as evidenced by the presence of large amounts of $\mathrm{Si}_{2} \mathrm{~N}$ $\mathrm{H}$ bonds at $\sim 3350 \mathrm{~cm}^{-1}$, which we believe limits the size of the clusters during growth. Considering this together with the XPS data for $R=0.05$ samples, we propose that the a-Si clusters are now smaller due to the presence of large amounts of $\mathrm{Si}-\mathrm{H}$ and $\mathrm{N}-\mathrm{H}$, which limits the growth of the clusters, which are now separated by a stronger matrix of a-Si:H and a$\mathrm{SiN}_{X}: \mathrm{H}$. This explains the shorter wavelength $\mathrm{PL}$ peak position of $\mathbf{R}=0.05$ samples when compared with the samples with $R=0$. The fact that, a lot of $H$ through $\mathrm{Si}_{2} \mathrm{~N}-\mathrm{H}$ still remains in the samples, explains the small red shifts observed upon 
annealing.

In conclusion, samples grown without $\mathrm{NH}_{3}$ show $P L$ in the near-IR, while those grown with $\mathrm{NH}_{3}$ have $P L$ in the green. Samples with $\mathbf{R}>0$ exhibit PL, which becomes stronger with annealing. In particular, samples grown with $R=0.05$ give strong visible $P L$, when annealed. Since no intentional $O$ was introduced during the growth and amealing, we conclude that $\mathrm{O}$ is not a necessary component of the PL mechanism. We suggest that, PL originates from Si clusters of differing sizes in common with sinilar results in $\mathrm{a}-\mathrm{SiO}_{\mathrm{X}}: \mathrm{H}^{7}$ These clusters are smaller in the case of samples grown with $\mathbf{R}>0$. High temperature annealing leads to increases in the sizes of these clusters as well as improving the crystallinity.

We are grateful to Prof. Şefik Süzer of the Chemistry Department for XPS measurements, Murat Güre for help with the sample preparation. We also gratefully acknowledge the support of this research by the Scientific and Technical Research Council of Turkey (TUBITAK) through Grant No : TBAG-1244.

References

1. A. Bsiesy et .al. Surf. Sci. 254, 195 (1991).

2. L.T. Canham, Appl. Phys. Lett. 57, 1046 (1990).

3. Optical Properties of Low Dimensional Silicon Structures, NATO ASI Series, 44, Eds:D.C.Bensahel, L.T.Canham, and S.Ossicini, Dordrecht, Kluwer (1993).

4. M.S.Brandt, H.D.Fuchs, M.Stutzmann, J.Weber, and M. Cardona, Solid State Commun. 81, 307 (1992).

5. M.W.Cole, J.F.Harvey, R.A.Lux, D.W.Eckert and R.Tsu, Appl. Phys. Lett. 60, 2800 (1992).

6. D.J.Wolford, B.A. Scoot, J.A. Reimer and J.A.Bradley, Physica B117, 920 (1983).

7. F.N.Timofeev, A.Aydınl, R. Ellialtioğlu, K. Türkoğlu, M. Güre, V.N.Mikhailov, andO.A. Lavrova, Solid State Commun. 95, 443 (1995).

8. M.H.Brodsky, Solid State Commun. 36, 55 (1980).

9. V. Petrova-Koch, T. Muschik, A. Kux, B.K.Meyer and F. Koch, Appl. Pliys. Lett. 61, 943 (1992).

10. X.Y.Hou, G.Shi, W. Wang, HF.L.Zhang, P.H.Hao,
D. M.Huang and X.Wang, Appl. Pliys. Lett. 62, 1097 (1993).

11. W.A.Lanford, and M.J.Rand, J.Appl. Phys. 49, 2473 (1978).

12. W. B. Pollard, and G.Lucovsky, Phys. Rev. B26, 3172 (1982).

13. W.-S. Liao, C.-H. Lin and S.-C. Lee, Appl. Phys. Lett. 65, 2229 (1994).

14. A. Morimoto, S. Oozara, M. Kumeda and T. Shimizu, Phys. Status Solidi B119, 715 (1983)

15. H.J.Stein, P.S.Peercy and R.J.Sokel, Thin Solid Films 101, 291 (1983).

16. J. Robertson, Philosophical Magazine B69, 307 (1994).

17. G. Lucovsky, J.Yang, S.S.Chao, J.E.Tyler, and W. Czubatyj, Phy. Rev. B28, 3243 (1983).

18.P.Bruesch,Th.Stockmeier, F.Stucki, P.A.Buffat,and J.K.N. Linder, J. Appl. Phys. 73, 7677 (1993).

19. R.Karcher, L.Ley and R.L.Johnson, Phys. Rev.B, 30, 1896 (1984). 